\title{
Wafer-scale fabrication and modification of silicon nano-pillar arrays for nanoelectronics, nanofluidics and beyond
}

\section{Dirk Jonker*, Lucas Kooijman and Yasser Pordeli}

Mesoscale Chemical Systems Chair, Faculty of Science and Technology, MESA+ Institute, University of Twente, P.O. Box 217, 7500 AE Enschede, The Netherlands Email: d.jonker@utwente.nl Email: 1.j.kooijman@utwente.nl Email: y.pordeli@utwente.nl

\section{Bernhard van der Wel}

Integrated Devices and Systems Chair,

Faculty of Electrical Engineering, Mathematics and Computer Science,

MESA+ Institute,

University of Twente,

P.O. Box 217, 7500 AE Enschede, The Netherlands

Email: b.y.vanderwel@utwente.nl

\section{Erwin Berenschot and Bjorn Borgelink}

Mesoscale Chemical Systems Chair,

Faculty of Science and Technology,

MESA+ Institute,

University of Twente,

P.O. Box 217, 7500 AE Enschede, The Netherlands

Email: j.w.berenschot@utwente.nl

Email: b.t.h.borgelink@utwente.nl

\section{Hai Le-The}

Physics of Fluids Chair,

Faculty of Science and Technology,

MESA+ Institute,

University of Twente,

P.O. Box 217, 7500 AE Enschede, The Netherlands

and 
BIOS Lab-on-a-Chip Chair,

Faculty of Electrical Engineering,

MESA+ Institute,

University of Twente,

P.O. Box 217, 7500 AE Enschede, The Netherlands

Email: h.lethe@utwente.nl

\section{Meint de Boer}

NanoLab Cleanroom,

MESA+ Institute,

University of Twente,

P.O. Box 217, 7500 AE Enschede, The Netherlands

Email: m.j.deboer@utwente.nl

\section{Jan Eijkel}

BIOS Lab-on-a-Chip Chair,

Faculty of Electrical Engineering,

Mathematics and Computer Science,

MESA+ Institute,

University of Twente,

P.O. Box 217, 7500 AE Enschede, The Netherlands

Email: j.c.t.eijkel@utwente.nl

\section{Ray Hueting}

Integrated Devices and Systems Chair,

Faculty of Electrical Engineering, Mathematics and Computer Science,

MESA+ Institute,

University of Twente,

P.O. Box 217, 7500 AE Enschede, The Netherlands

Email: r.j.e.hueting@utwente.nl

\section{Roald Tiggelaar}

NanoLab Cleanroom,

MESA+ Institute,

University of Twente,

P.O. Box 217, 7500 AE Enschede, The Netherlands

Email: r.m.tiggelaar@utwente.nl 


\title{
Arie van Houselt
}

Physics of Interfaces and Nanomaterials Chair,

Faculty of Science and Technology,

MESA+ Institute,

University of Twente,

P.O. Box 217, 7500 AE Enschede, The Netherlands

Email: a.vanhouselt@utwente.nl

\section{Han Gardeniers and Niels Tas*}

Mesoscale Chemical Systems Chair, Faculty of Science and Technology, MESA+ Institute, University of Twente, P.O. Box 217, 7500 AE Enschede, The Netherlands

Email: j.g.e.gardeniers@utwente.nl

Email: n.r.tas@utwente.nl

${ }^{*}$ Corresponding authors

\begin{abstract}
We report on the fabrication and modification of a top-down nanofabrication platform for enormous parallel silicon nanowire-based devices. We explain the nanowire formation in detail, using an additive hybrid lithography step, optimising a reactive ion etching recipe for obtaining smooth and vertical nanowires under a hybrid mask, and embedding the nanowire in a dielectric membrane. The nanowires are used as a sacrificial template, removal of the nanowires forms arrays of well-defined nano-pores with a high surface density. This platform is expected to find applications in many different physical domains, including nanofluidics, (3D) nanoelectronics, as well as nanophotonics. We demonstrate the employment of the platform as field emitter arrays, as well as a state-of-the-art electro-osmotic pump.
\end{abstract}

Keywords: 3D nanofabrication; 3D nanoelectronics; nanofluidics; electro-osmotic pump; nanoelectronics; additive hybrid lithography; SiNW; silicon nanowires; continuous mode; mixed-mode; reactive ion etching.

Reference to this paper should be made as follows: Jonker, D., Kooijman, L., Pordeli, Y., van der Wel, B., Berenschot, E., Borgelink, B., Le-The, H., de Boer, M., Eijkel, J., Hueting, R., Tiggelaar, R., van Houselt, A., Gardeniers, H. and Tas, N. (2020) 'Wafer-scale fabrication and modification of silicon nano-pillar arrays for nanoelectronics, nanofluidics and beyond', Int. J. Nanotechnol., Vol. 17, Nos. 7/8/9/10, pp.583-606.

Biographical notes: Dirk Jonker received his BSc in Applied Physics Cum laude and with honours at Saxion University of Applied Sciences in 2018. That year he also received the NNV HBO Young Talent prize awarded by The Netherlands Physical Society (NNV). During his BSc studies, he focused on improving polymeric valves for microfluidics, surface modification for improved protein adhesion on polymeric substrates in heart-on-a-chip devices, and the design and realisation of a nanostructured water condenser aiming for integration in a hydrogen generator. Currently, he is a doctoral candidate at the Mesoscale Chemical Systems (MCS) chair at the University of Twente working on the nanoscale fabrication of a field emitter device. 
Lucas Kooijman received his MSc in Electrical Engineering from the University of Twente, Netherlands, in 2019. Alongside his education he also worked first in the BIOS Lab-on-a-Chip group, MESA+ Institute, University of Twente, and later in the Applied Microfluidics for BioEngineering Research (AMBER) group, MESA+ Institute, University of Twente, as a Researcher working on electroporation of synthetically created cell membranes or bilayer lipid membranes (BLM) and the development of a microfluidic system for creating BLMs. After getting his MSc, he worked as a researcher (9 months) at the (AMBER) group working on the development of a tumour-on-a-chip microfluidic platform with integrated electrochemical sensors. He is now working as a researcher at the Mesoscale Chemical Systems (MCS) group, MESA+ Institute, University of Twente, focussing on controlled nanomachining of antibacterial nanostructures in titanium for medical applications.

Yasser Pordeli received his BSc in Advanced Technology from the University of Twente, the Netherlands, 2016. He then followed the Master Track Nanotechnology and received his MSc from the University of Twente, the Netherlands, in 2019. Currently, he works as a PhD candidate at the Mesoscale Chemical Systems (MCS) research group at the University of Twente, MESA+ institute, the Netherlands. His work focus on nanomachining technologies for $3 \mathrm{D}$ racetrack memory applications.

Bernhard van der Wel is a $\mathrm{PhD}$ candidate at the Integrated Devices and Systems (IDS) research group, MESA+, University of Twente, The Netherlands. He received his BSc in Advanced Technology in 2016 and his MSc in Nanotechnology in 2019 from the University of Twente, the Netherlands. During his studies, he firstly investigated THz-frequency tunnelling diodes based on geometrical asymmetry, and thereafter designed and fabricated a unique miniaturised Trench-Metal-Oxide-Semiconductor (TMBS) diode, based on full-wafer arrays of Silicon vertical Nanowires (SiNWs). His fundamental interest is developing progressive semiconductor devices using advanced fabrication techniques in the realm of 3D-nanoshaping. Currently, he pursues a $\mathrm{PhD}$ in Material Science, researching new techniques facilitating Atomic Layer Deposition (ALD) of uncharted materials.

Erwin Berenschot received his BSc in Applied Physics from the Technische Hogeschool in Enschede, The Netherlands, in 1990. From 1992 to 2013, he has been employed as a Cleanroom Engineer at the Transducer Science and Technology group of the MESA+ Institute. In 2014, he moved to the Mesoscale Chemical Systems group of MESA+. His key-expertise includes all aspects of silicon-based micro-nanomachining. He contributed to the invention of the UT nano-fountain pen in 2004. In 2005, he was co-inventor of corner lithography and in 2007 he was involved in the development of edge lithography, which results in 2009 in the development of wafer-scale fabricated free-standing silicon tetrahedral (quantum) dots, followed by the development of self-multiplying fractal machining of silicon in 2012. In recent years he delivered key contributions to the development of the UTwente 3D "crystallographic nanolithography" platform. Berenschot has co-authored over 190 peer-reviewed papers ( $>3400$ citations, Scopus, excl. self-citations, h-index 30) and 10 patents.

Bjorn Borgelink received his MSc in Applied Physics from the University of Twente, The Netherlands, in 2017. He now is working as a PhD student at the Mesoscale Chemical Systems group, MESA+ Institute, University of Twente, 
The Netherlands. His research entails but is not limited to, improving electrospinning by novel microsized fluidic nozzles and modelling of (near-field) electrospinning.

Hai Le-The received his BSc in Electronics and Telecommunication Engineering from Bach Khoa University, Vietnam, in 2012, and his MSc in Micro and Nano Systems Technology from the University of South-Eastern Norway in 2014. He then worked as a researcher (5 months) at the Institute for Computational Science (INCOS), Ton Duc Thang University, Vietnam. In 2015, he started his PhD research within the Netherlands Center for Multiscale Catalytic Energy Conversion (MCEC) in the BIOS Lab-on-a-Chip group, MESA+ Institute, University of Twente, the Netherlands. In 2019, he graduated with a Doctorate Cum Laude degree. He is now working as a postdoctoral researcher in the Physics of Fluids group, MESA+ Institute, University of Twente, the Netherlands, focusing on nanomachining nanoscale sensing devices for turbulence measurements.

Meint de Boer is a Process Technologist in the field of Micro (Nano) Technology at the MESA+ Institute for Nanotechnology at the University of Twente. His field of interests are the development of new "process windows" for dry etching of all kind materials, development of process flows concepts for Micro (Nano) Technology applications and development of methods how to document equipment and processes in a multi-application cleanroom (databases). Currently, he is project leader of setting-up a new platform for sharing processes and dry etching equipment for the EuroNanoLab consortium.

Jan Eijkel received his MSc in Pharmacy at the University of Amsterdam and his PhD in 1995 at the University of Twente with Prof. Dr. Piet Bergveld. After a postdoc at Imperial College London with prof. Andreas Manz, he joined the BIOS/Lab on a Chip croup at the University of Twente where he became Full Professor Nanofluidics for Lab on a Chip Applications in 2010. The focus of his research is the investigation of physicochemical phenomena in micro- and nanofluidic systems, and their practical applications e.g. in Point of Care systems. These investigations include capillary phenomena such as filling and drying, osmosis, o/w two-phase flow, transport and separation of ions and DNA and fluidic energy generation. He is an Editor of the Springer-nature journal Microfluidics and Nanofluidics.

Ray Hueting obtained his Master (Cum laude) and his $\mathrm{PhD}$ in Electrical Engineering from Delft University, the Netherlands in 1992 and 1997, respectively. He then joined Philips (locations Nijmegen, Eindhoven and Leuven) to work on power and RF device modelling, design and characterisation. In 2004, he joined the University of Twente (UT) and has been an Associate Professor since 2011. His main interest is semiconductor device physics and modelling of novel semiconductor devices for power, CMOS, and optical applications. He is (co)inventor of various devices, such as the piezoelectric field-effect transistor as a steep-subthreshold switch, the charge-plasma diode, the superjunction light-emitting diode and optocouplers in commercial CMOS. He holds 35 U.S. patents in the field of power and RF devices and authored and co-authored more than 90 papers. He has served on the technical program committee member of the ISPSD and ESSDERC.

Roald Tiggelaar (1976) received his MSc in Electrical Engineering in 2000 and his $\mathrm{PhD}$ in 2004, both from the University of Twente. Afterwards, he joined the Mesoscale Chemical System group as a postdoctoral researcher. From mid2010 to mid-2011 he was employed at iX-factory GmbH (Dortmund, Germany) as process and design-engineer. He then rejoined the University of Twente, 
where is currently a staff member and researcher micro/nanotechnology at the MESA+ NanoLab cleanroom. His research interests include micro/nanofabrication and -fluidics, MEMS, materials science and development of novel silicon-based top-down micro/nanofabrication techniques and applications. He has (co-)authored more than 70 journal papers.

Arie van Houselt ( $\mathrm{PhD}$ in surface science 2008) works as an Assistant Professor at the University of Twente. He utilises tunnelling electrons (scanning tunnelling microscopy) and an electron beam (low energy electron microscopy) to study properties of crystalline semiconductor and metal surfaces. He has a broad interest in interfacial properties, ranging from wetting and catalysis to two-dimensional materials.

Han Gardeniers obtained an MSc in Chemistry and a PhD in Experimental Solid-State Physics from Radboud University Nijmegen, The Netherlands, in 1985 and 1990, respectively. He was employed as an Assistant Professor (UD) in the field of Micromechanical Transducers at the University Twente, The Netherlands, from 1990 to 2001, after which he has worked in the industry, as a Senior Scientist at Kymata Ltd./Alcatel Optronics and Micronit Microfluidics, from 2001 till 2003. He rejoined the University of Twente as an Associate Professor (UHD) with the Biosensors/Lab-on-a-Chip Group in 2003. In 2007 he became a Full Professor and started his research group "Mesoscale Chemical Systems". This group focuses on micro and nanostructures for chemical applications, including microreactors and microfluidic systems for chemical analysis. His teaching activities are within the Chemical Engineering field. He received a personal NWO Vici grant in 2004 and an ERC Advanced Grant in 2017 and co-authored over 250 journal papers and 11 patents.

Niels Tas, who was originally trained as an Electrical Engineer, received his $\mathrm{PhD}$ from the University of Twente (UT) in April 2000, on the topic of design and realisation of MEMS linear electrostatic motors. In 2004, he was appointed as an Assistant Professor at the Transducers Science and Technology group at the UT, and as an Associate Professor in 2010. In 2008, he was awarded an NWO personal Vidi-grant which he used to further develop new 3D-nanofabrication techniques for application in advanced scanning probe microscopy and beyond. Since 2014, he is working in the Mesoscale Chemical Systems group at the University of Twente, headed by Prof. Dr. Han Gardeniers. His research interests focus on the application of innovative 3D-nanofabrication techniques in the fields of nanofluidics, NEMS, nano-electronics and photovoltaics.

This paper is a revised and expanded version of a paper entitled 'Wafer scale fabrication and modification of silicon nano-pillar arrays for nanoelectronics, nanofluidics and beyond' presented at IWNA 2019 Conference, Phan Thiet, Vietnam, 6-9 November, 2019. Parts of this paper have been presented at the 2019 MNE Conference, Rhodes, Greece, 23-26 September, 2019, and the 2019 $\mu T A S$ Conference, Basel, Switzerland, 27-31 October, 2019.

\section{Introduction}

Crystalline vertical silicon nanowires (SiNW), also referred to as silicon nano-pillars, are already known as key building blocks for ultrahigh density electronic integrated circuits. An example is the implementation in high areal density memory chips (3D-NAND technology), other examples of applications are e.g., vacuum electronics, display 
technology, or field emitters in multi-beam electron lithography [1-3]. In the context of energy harvesting systems, we have developed a 'curved' metal - insulator semiconductor (cMIS) tunnel diode based on nano-pillar technology [4].

Besides being used as the functional device area, the SiNW structure can also be used as a template for other applications. An example is by embedding the SiNWs in a dielectric ceramic material, typically low-stress silicon-rich silicon nitride (SiRN), that can be deposited through low-pressure chemical vapour deposition (LPCVD) [5]. Furthermore, since the SiNWs are fabricated from a single crystal, they can be machined by a combination of anisotropic etching and self-aligned nano-patterning techniques such as corner lithography [6,7]. We refer to this combination as crystallographic nanolithography [8]. The embedding in a dielectric, mechanical stable membrane enables access to the nano-pillars from both sides (top and bottom). An intriguing aspect of the resulting configuration is that free-standing ceramic membranes can be obtained, at designated locations on the substrate, paving the road towards novel electronic configurations, as well as nanofluidic device configurations in which typically the nanopillars are sacrificed to create arrays of well-controlled nano-pores.

In this study, the goal is to fabricate SiNWs with control over the morphology of the sidewall. Furthermore, we explore the etching of these SiNWs at device areas of varying size, being anywhere between the full-wafer-scale $\left(\right.$ several $\mathrm{cm}^{2}$ ) and areas of a few $\mu \mathrm{m}^{2}$, while minimising the total processing time for a single substrate. To achieve this, we introduce an alternative fabrication route for single-crystalline high density $\left(1.6 \times 10^{9} \mathrm{~cm}^{-2}\right)$ SiNW devices, based on the combination of displacement Talbot lithography (DTL), novel additive hybrid lithography, and nanoscale reactive ion etching (RIE) in a mixed-mode RIE process at non-cryogenic temperature, using fluor(carbon)-chemistry for etching and passivation. Next to this, two realised examples will be shown to illustrate possible practical implementations of the developed SiNWs in nanotechnology.

The first example is the fabrication of a large area of field emitter (LAFE) by an additive hybrid lithography process that merges a DTL nanoscale pattern with an i-line photoresist microscale pattern, yielding a combined photoresist pattern in a highthroughput fashion [9]. The hybrid resist pattern is then transferred into the silicon substrate using an optimised RIE process to create a LAFE based on SiNWs. Applications using this LAFE technology include e.g., novel light sources [10], electron microscopy [11], and flat panel displays [12].

The second example utilises sacrificial nano-pillar moulding. A manufacturing process has been developed for manufacturing massively parallel $\left(\sim 1.6 \times 10^{9}\right.$ nanopores per $\mathrm{cm}^{2}$ ) electro-osmotic flow (EOF) pumps in silicon nitride. The technique enables a high pore density and well-controlled pore dimensions resulting in a high-throughput pump at low actuation voltages [13]. Microfluidic pumps are used in many fields including healthcare, science, measurement equipment and future chip cooling [14,15].

\section{Experimental}

\subsection{General procedure}

A step-by-step representation of the fabrication procedure is shown in Figure 1 via schematic cross-sections of the substrate after the application of the sequential fabrication 
steps. Key steps in the fabrication procedure are the implementation of DTL for rapid and uniform patterning of a photoresist layer at the wafer-scale [16], RIE of a bottom anti-reflective coating [17], the implementation of an additive hybrid lithography step which will be discussed in the following paragraph, and RIE of silicon.

Figure 1 Images (a)-(i) show a schematic representation of the cross-section of the substrate to illustrate the different fabrication steps. In the top right corner, a legend is shown that indicates the materials corresponding to the colours used in the schematic drawings (see online version for colours)

a)

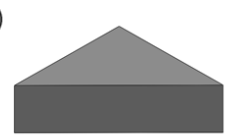

b)

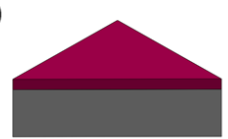

c)

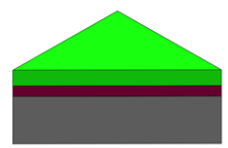

d)

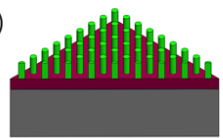

e)
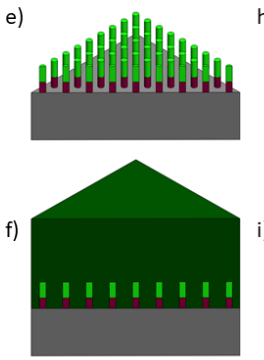

g)

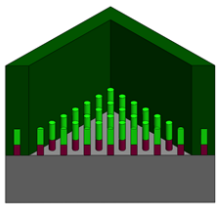

h)
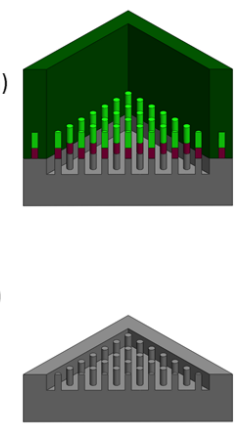

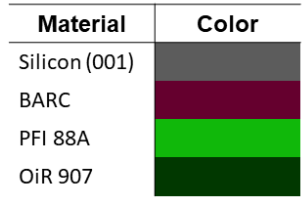

$\left.h_{1}\right)$

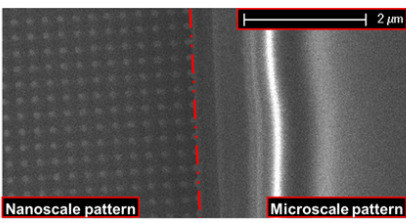

$\left.\mathrm{i}_{1}\right)$

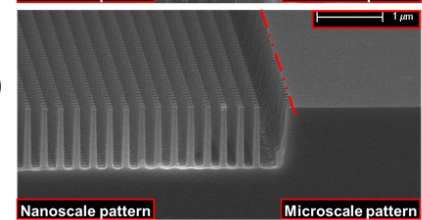

A $100 \mathrm{~mm}$ silicon $<001>$ substrate, Figure 1(a), was first spin-coated with a layer of bottom anti-reflective coating (BARC, Barli-II, AZ microchemicals) for $45 \mathrm{~s}$ at $3000 \mathrm{rpm}$, followed by pre-baking on a hot-plate at $180^{\circ} \mathrm{C}$ for $60 \mathrm{~s}$, Figure 1(b). In the subsequent step, a positive tone i-line photoresist (PFI-88a, PGMEA 1:1, Sumitomo) was spun on top at $4000 \mathrm{rpm}$ for $45 \mathrm{~s}$ and pre-baked at $90^{\circ} \mathrm{C}$ for $60 \mathrm{~s}$, Figure 1(c)). The resist was exposed twice at perpendicular angles for $45 \mathrm{~s}$ according to the orthogonal DTL procedure (oDTL) [17]. After exposure, the substrate was post-baked at $110^{\circ} \mathrm{C}$ for an additional $60 \mathrm{~s}$ and sequentially developed in a solution of TMAH (OPD4262, Arch Chemicals) for two times $30 \mathrm{~s}$ in separate beakers, rinsed in a quick-dump rinser (QDR) and spin-dried. The substrate now contains an array of photoresist nanodots with a square unit cell of $250 \mathrm{~nm}$ pitch, $100 \mathrm{~nm}$ in diameter, and $\sim 270 \mathrm{~nm}$ high, patterned at the full-wafer-scale as shown in Figure 1(d)).

The substrate was moved to a plasma-etcher (TEtske, home-built at MESA+ institute) where RIE was performed in a nitrogen $\left(\mathrm{N}_{2}\right)$ plasma to transfer the resist pattern into the BARC layer directionally and at the wafer-scale [17]. Before starting the $\mathrm{N}_{2}$ RIE, the plasma chamber was cleaned thoroughly with acetone and isopropanol-soaked wipes after which an oxygen $\left(\mathrm{O}_{2}\right)$ plasma cleaning was performed for $10 \mathrm{~min}$. Since the BARC layer can be etched isotropic by the remaining $\mathrm{O}_{2}$ species, [17], it is important to perform a cycle with an $\mathrm{N}_{2}$-plasma on an empty chamber to minimise $\mathrm{O}_{2}$ species in the gas supply lines. Before starting the plasma process, the chamber was pumped down to $3 \times 10^{-1}$ mTorr. The process conditions for performing the $\mathrm{N}_{2}$ RIE are a chamber pressure 
of $13 \mathrm{mTorr}, 50 \mathrm{sccm} \mathrm{N}_{2}$ supply, $25 \mathrm{~W}$ of capacitively coupled plasma power (CCP), yielding a DC potential of $\sim 252 \mathrm{~V}$. The RIE was performed for 08:30 (mm:ss) yielding a nanopatterned BARC+PFI coated substrate, at the full wafer-scale, represented in Figure 1(e)).

\subsection{Additive hybrid lithography (only for the LAFE)}

An i-line positive tone photoresist (OiR 907, Fujifilm electronic materials) was spun at $4000 \mathrm{rpm}$ for $45 \mathrm{~s}$ and pre-baked at $95^{\circ} \mathrm{C}$ for $60 \mathrm{~s}$, Figure 1(f)). Exposure was commenced under a mask at a mask-aligner (EVG 620, EV Group) for $4.5 \mathrm{~s}$ at an exposure intensity of $12 \mathrm{~mW} / \mathrm{cm}$ at $365 \mathrm{~nm}$. Afterward, the resist film was developed in OPD4262 in two sequential cycles of $30 \mathrm{~s}$ in separate beakers, and finally rinsed in a QDR and spin-dried to yield the hybrid resist pattern as shown in Figure $1(\mathrm{~g})$ ).

\subsection{RIE of silicon in a mixed-mode $\mathrm{SF}_{6} ; \mathrm{C}_{4} \mathrm{~F}_{8}$ plasma}

The patterned substrate was moved to a plasma-etcher (Plasma Pro 100 Estrelas, Oxford instruments) to transfer the hybrid mask pattern into the silicon substrate using a mixedmode sulphur hexafluoride + perfluorocyclobutane $\left(\mathrm{SF}_{6}+\mathrm{C}_{4} \mathrm{~F}_{8}\right)$ RIE process. Before etching was conducted, first the temperature of the plasma chamber was checked. If the temperature of the lower part of the plasma chamber is higher than 180 degrees, it induces an increased etch-rate and undercut during etching. Secondly, a cleaning program was run which performs an $\mathrm{O}_{2}$ plasma cleaning of the plasma chamber for $15 \mathrm{~min}$. Thirdly, a $5 \mathrm{~min}$ run was conducted on a dummy substrate at process conditions to remove residual $\mathrm{O}_{2}$ from the plasma-chamber. Simultaneously, the native oxide was removed from the patterned substrates during a batch process in a freshly prepared $1 \%$ aqueous hydrofluoric acid (HF) solution for $45 \mathrm{~s}$, after which they are QDR, and spin-dried individually. Note that the substrates were immediately processed to prevent the regrowth of the native oxide layer and consequential etching inhomogeneities. The hybrid patterned substrate was processed at the conditions as listed in Table 1 giving rise to the SiNW structure as displayed in Figure 1(h)). Next, the substrates were cleaned in an $\mathrm{O}_{2}$ plasma with $800 \mathrm{~W}$ plasma power for $1 \mathrm{~h}$ (TEPLA 300E), followed by RCA-2 cleaning hydrogen chloride: hydrogen peroxide: water $\left(\mathrm{HCl}: \mathrm{H}_{2} \mathrm{O}_{2}: \mathrm{H}_{2} \mathrm{O}(1: 1: 5)\right)$, and a $30 \mathrm{~s} \mathrm{1 \%} \mathrm{HF} \mathrm{dip} \mathrm{yielding} \mathrm{the} \mathrm{substrate} \mathrm{as} \mathrm{shown} \mathrm{in} \mathrm{Figure} \mathrm{1(i)).}$

Table 1 Process settings for conditioning the plasma during RIE of silicon. Experiments were conducted by varying the settings during the etch-step. A range is stated over which the different settings were tested to characterise the etching process (see paragraph 3.2 and Table 2)

\begin{tabular}{lccccccc}
\hline Step & $\begin{array}{c}\text { Setting } \\
\text { power } \\
(\mathrm{W})\end{array}$ & $\begin{array}{c}C C P \\
\text { power } \\
(\mathrm{W})\end{array}$ & $\begin{array}{c}\text { Pressure } \\
(\mathrm{mTorr})\end{array}$ & $\begin{array}{c}\text { SF } F_{6} \text { flow } \\
(\mathrm{sccm})\end{array}$ & $\begin{array}{c}C_{4} F_{8} \\
\text { flow } \\
(\mathrm{sccm})\end{array}$ & $\begin{array}{c}\text { Time } \\
(\mathrm{mm}: \mathrm{ss})\end{array}$ & $\begin{array}{c}\text { Backside } \\
\text { pressure } \\
(\text { Torr })\end{array}$ \\
\hline Load & 0 & 0 & $10^{-4}$ & 0 & 0 & $03: 00$ & 0 \\
Gas on & 0 & 0 & 18 & 9.7 & 20.3 & $00: 10$ & 10 \\
Ignite & 1200 & 30 & 18 & 19.4 & 40.6 & $00: 02$ & 10 \\
Etch & 800 & $35-41$ & $16-22$ & $20-26$ & $42-48$ & $01: 00-03: 00$ & 10 \\
Pump down & 0 & 0 & $10^{-4}$ & 0 & 0 & 0 & 0 \\
\hline
\end{tabular}


To achieve LAFE test devices, after cleaning of the nanowires, $500 \mathrm{~nm}$ of silicon dioxide $\left(\mathrm{SiO}_{2}\right)$ was deposited by LPCVD of tetraethyl orthosilicate (TEOS) at $725^{\circ} \mathrm{C}$. The $\mathrm{SiO}_{2}$ layer was patterned by conventional UV-photolithography and subsequently etched in $1 \%$ $\mathrm{HF}$ yielding a $500 \mathrm{~nm}$ spacer layer on the flat surface of the $<001>\mathrm{Si}$ substrate. Additionally, a $1 \times 1 \mathrm{~cm}^{2}$ plateau was created by bulk RIE of silicon in a $\mathrm{SF}_{6} ; \mathrm{C}_{4} \mathrm{~F}_{8}$ plasma under a photoresist mask. Careful alignment before exposure coincides the centres of the plateau and the LAFE device. Lastly, the substrate was cleaned again in an $800 \mathrm{~W} \mathrm{O}_{2}$ plasma for $1 \mathrm{~h}$, followed by RCA-2 cleaning and subsequent HF dip, as described before. The thus produced substrate is shown in Figure 8.

\subsection{Fabrication of massively parallel electro-osmotic flow (EOF) pumps in silicon nitride}

The SiNWs were fabricated at the wafer-scale by RIE of silicon under a nanopatterned mask, as described in Sections 2.1 and 2.3, thus negating the additive hybrid lithography step. Next, wet thermal oxidation of the SiNW array was performed at $800^{\circ} \mathrm{C}$ to grow a $10 \mathrm{~nm}$ thick layer of $\mathrm{SiO}_{2}$, as shown in Figure 2(a)). Sequential deposition of $500 \mathrm{~nm}$ SiRN by LPCVD at $850^{\circ} \mathrm{C}$ and $50 \mathrm{~nm}$ of polysilicon (poly-Si) by LPCVD at $590^{\circ} \mathrm{C}$ and converting a part of the poly-silicon in a $10 \mathrm{~nm}$ thick silicon oxide layer by wet thermal oxidation at $800^{\circ} \mathrm{C}$, yield SiNWs embedded in a ceramic membrane which is covered by a poly-Si/ $\mathrm{SiO}_{2}$ hard mask.

Figure 2 Summarised schematic representation of the membrane production. Red: SiRN; Turquoise: $\mathrm{SiO}_{2}$; Dark grey: $<100>$ silicon; Light grey: Poly-Si. (a) Nanopillars coated with $\mathrm{SiO}_{2}$. (b) Windows etched in Sin by H3PO4 wet etching. (c) Single sided etching of bulk silicon by wet KOH etching. (d) Sacrificing bulk silicon nanopillars creating nanopores by wet TMAH etching. (e) Nanopores filled with silicon and oxidised as a hard mask. (f) Exposing the still closed $\mathrm{SiO}_{2}$ caps of the nanopores. (g) Finalised membrane (see online version for colours)
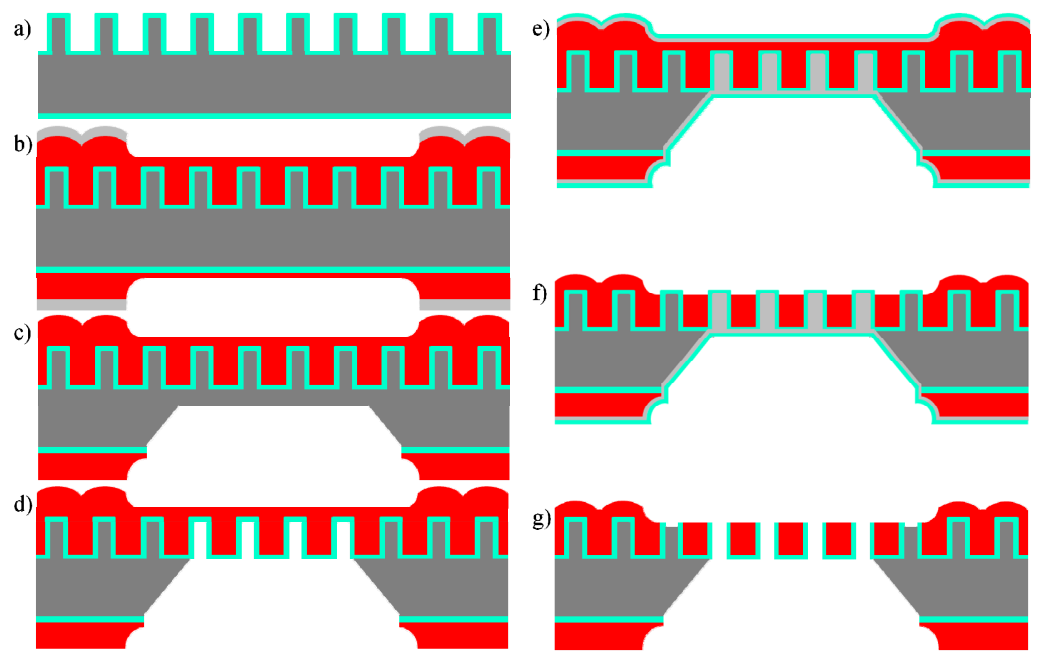

Source: Kooijman et al. [13]

Patterning of the hard mask was done by conventional UV-photolithography, opening the resist locally to create several $100 \times 100 \mu \mathrm{m}^{2}$ windows. Subsequent etching of the 
thermally grown oxide in buffered HF (BHF) (1:7), stripping off the resist in $99 \%$ nitric acid $\left(\mathrm{HNO}_{3}\right)$, a $1 \% \mathrm{HF}$ dip to remove the chemically grown $\mathrm{SiO}_{2}$ and etching of the poly-Si in tetramethylammonium hydroxide (TMAH) at $70^{\circ} \mathrm{C}$, and etching of the SiRN in $85 \%$ sulfuric acid $\left(\mathrm{H}_{3} \mathrm{PO}_{4}\right)$ at $180^{\circ} \mathrm{C}$ defined the window in which the nanopores were formed, as displayed in Figure 2(b). The masked areas define the supporting structure.

SiRN was removed from the back side by RIE in fluoroform $\left(\mathrm{CHF}_{3}\right)$ and oxygen $\left(\mathrm{O}_{2}\right)$ after which the remaining $\mathrm{SiO}_{2}$ is stripped in BHF. The bulk silicon is etched single-sided in $25 \%$ potassium hydroxide $(\mathrm{KOH})$ at $75^{\circ} \mathrm{C}$ until $80 \mu \mathrm{m}$ was left, Figure 2(c)). The remaining silicon including the nanopillars was etched in $25 \% \mathrm{TMAH}$ at $70^{\circ} \mathrm{C}$, thus creating at the front side closed nanopores, Figure 2(d)). The front side closed nanopores were filled by LPCVD of $100 \mathrm{~nm}$ poly-Si which was immediately oxidised at $800^{\circ} \mathrm{C}$ yielding a $5 \mathrm{~nm}$ thick silicon oxide layer (on top of the poly-Si), a cross-section is shown in Figure 2(e)).

After protecting the back side with dicing foil (SWT10, Nitto), the $\mathrm{SiO}_{2}$ on the front side was removed with BHF. After the dicing foil was removed, the front side poly-Si was etched in $25 \% \mathrm{TMAH}$ at $70^{\circ} \mathrm{C}$ followed by the etching of the front side SiRN in $\mathrm{H}_{3} \mathrm{PO}_{4}$ at $180^{\circ} \mathrm{C}$, exposing the initially grown thermal oxide on top of the SiNW. A timed etch of this oxide in BHF, followed by removal of the poly-Si in $25 \% \mathrm{TMAH}$ at $70^{\circ} \mathrm{C}$, opens the nanopores while maintaining the initially grown thermal oxide at the sidewalls of the SiNWs, Figure 2(f)).

The $\mathrm{SiO}_{2}$ covering the embedded nanopores at the bottom side of the substrate was removed with BHF, followed by the etching of the poly-Si in $25 \% \mathrm{TMAH}$ at $70^{\circ} \mathrm{C}$, thereby opening and emptying the nanopores to create the functional membrane for EOF pumping, Figure 2(g)).

\section{Results and discussion}

After performing oDTL and RIE of the BARC layer, the substrate contains patterned PFI+BARC columns at the full-wafer-scale, as indicated in Figure 1(e) [17]. At this point, further processing may imply etching of silicon in a RIE process directly to acquire SiNWs at the full-wafer-scale (used for further processing upon fabrication of the EOF pumps), or by performing additive hybrid lithography to confine the nanodot pattern to appointed locations yielding functional device areas (important for the LAFE fabrication).

\subsection{Additive hybrid lithography}

In the following, the substrate is additionally patterned with photoresist to partially expose the patterned substrate. The results are shown in Figure 3. The contact line of the OiR 907 resist is well defined Figure 3(a), the viscosity of this resist prevents observable creep or wicking behaviour between the PFI+BARC columns. This enables the transfer of the mask pattern into the silicon at designated locations instead of at the wafer-scale. Moreover, the application of the process steps in Section 2.2, such as the baking and development, did not alter the integrity of the PFI+BARC columns. However, this approach did translate into the edge effect seen after RIE of silicon Figure 3(b). To minimise the effect, improved alignment may deliver a sharper edge and free-standing PFI+BARC columns. When not properly aligned, the nanopattern is partially 
incorporated at the transition Figure 3b). Figure 3c) displays a realised mix of microscale and nanoscale patterns and evidence the applicability of additive hybrid lithography. Additive hybrid lithography combines the oDTL PFI resist with an additional OiR 907 resist layer that confines the full wafer-scale nanopattern to a macroscopic area and designates functional device areas by partially exposing the nanopattern.

Figure 3 Results after applying the additive hybrid patterning step. (a) SEM image of the topview of a hybrid patterned substrate before RIE of silicon, step g) in Figure 1. The dashed bar indicates the transition line between the nanoscale and microscale pattern, being the exposed PFI+BARC columns and the patterned OiR 907 photoresist, respectively. (b) A cross-sectional view of a hybrid patterned substrate obtained through SEM, taken after RIE and stripping of the BARC and resist, step i) in Figure 1. (c) Top view of a more complex hybrid pattern achieved by SEM. In (a) and (b) the scale bars represent $1 \mu \mathrm{m}$, in (c) the scale bar represents $100 \mu \mathrm{m}$ (see online version for colours)
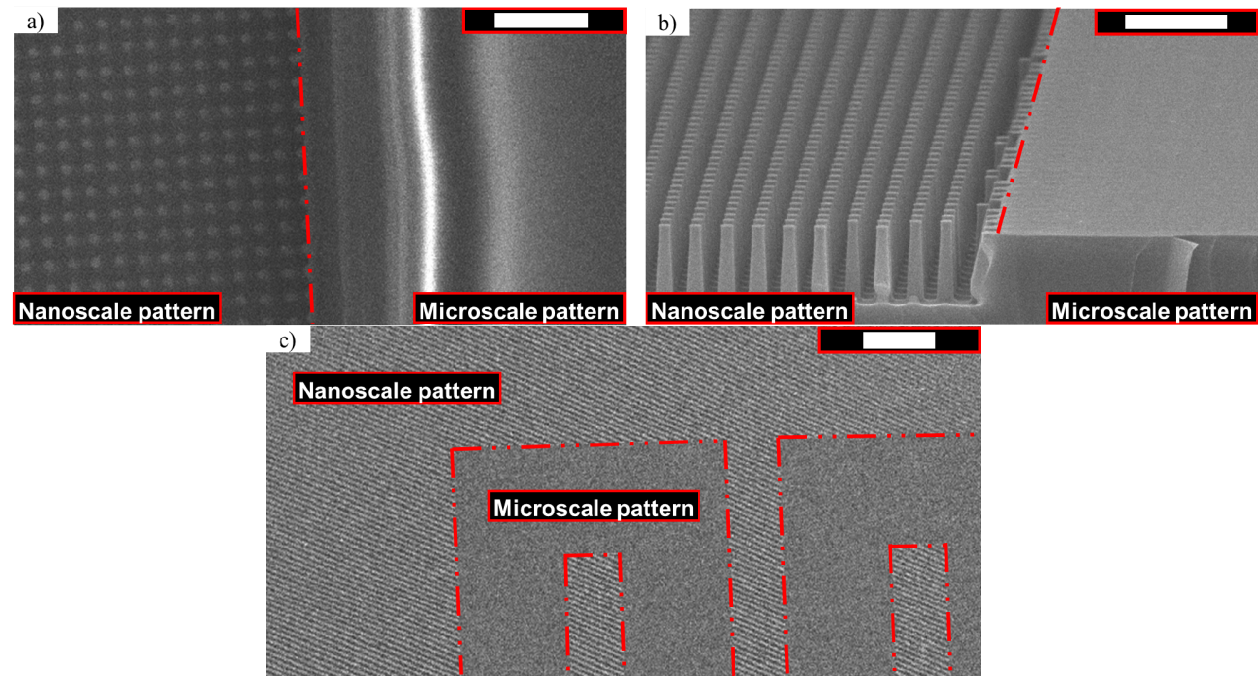

\subsection{Introduction and approach to RIE of silicon}

Typical for (D)RIE processes is the usage of both chemically active and passivating species during the ion bombardment to enhance the etch-rate and achieve directionality [18]. (D)RIE techniques can be differentiated by the types of gasses used during the etching process, and the order in which the ionised gas flows are directed towards the surface [19-21]. A differentiation can be made between the Bosch-process, also called pulsed-mode or gas chopping method, in which etching and passivating species are introduced sequentially to the plasma chamber [19], and the continuous process, also called the mixed-mode method [20], where the etching and passivating species are provided simultaneously to the plasma chamber. Although all techniques are based on ionising species and sequential transport to the substrate under the application of a (dynamic) electric field, different processes result in different outcomes [21-25].

In general, the process gas flows and parameterisation of the plasma conditions are altered according to the substrate and mask material, the loading which is defined later in this paragraph, and the desired morphological appearance of a single structure [26,27]. Part of optimising a dry-etching process may also entail minimising wafer-scale 
variation, being variations in the morphological appearance of an ensemble of structures. However, dry-etching techniques are inherently prone to wafer-scale variation due to temperature variations [28]. Moreover, when designing a device structure and accompanying fabrication procedure, one considers the selectivity (ratio of the etch-rate of the material over the etch-rate of the mask material) of the materials and the etchants used. Before getting into the results, some explanation is given about the varied process parameters, ones that are kept constant, and the different terminology used for describing the effect of the plasma conditioning on the morphological appearance.

The different process conditions (CCP Power, chamber pressure, $\mathrm{SF}_{6}$ flow, $\mathrm{C}_{4} \mathrm{~F}_{8}$ flow and the etch time) are listed in Table 2. Adjusting the CCP power regulates the power applied to the platen and also controls the DC bias between the plasma and the substrate which is RF modulated at $13.56 \mathrm{MHz}$. The pressure in the process chamber is achieved by actuating the automated pressure control unit that is placed between the process chamber and the turbomolecular pump. The valve position is a function of the applied pressure, the mass flow of the reactants, being the etching gas flow $\left(\mathrm{SF}_{6}\right)$, the passivating gas flow $\left(\mathrm{C}_{4} \mathrm{~F}_{8}\right)$, and the resultant etching products. The ICP power and chuck temperature are kept constant at $800 \mathrm{~W}$ and $0^{\circ} \mathrm{C}$, respectively. Thermal contact with the substrate is maintained by applying a back-side pressure of 10 Torr to the mechanically clamped substrate by regulating a helium mass flow. The heated liner temperature is set at a $120^{\circ} \mathrm{C}$ minimum, however, it is not actively cooled. A simplified schematic representation of the plasma chamber is given in Figure 4.

Figure 4 Schematic representation of the etching setup, (a), explaining the mixed-mode etching process, and a reference for the different terms used for the sidewall morphology (i)-(iii), being tapering, barrelling, and under-etch, respectively. (b)-(c) SEM images of SiNWs achieved by applying the plasma conditions listed in Table 2 run 1.1 and run 1.3 , scale bars represent $500 \mathrm{~nm}$ and $200 \mathrm{~nm}$, respectively
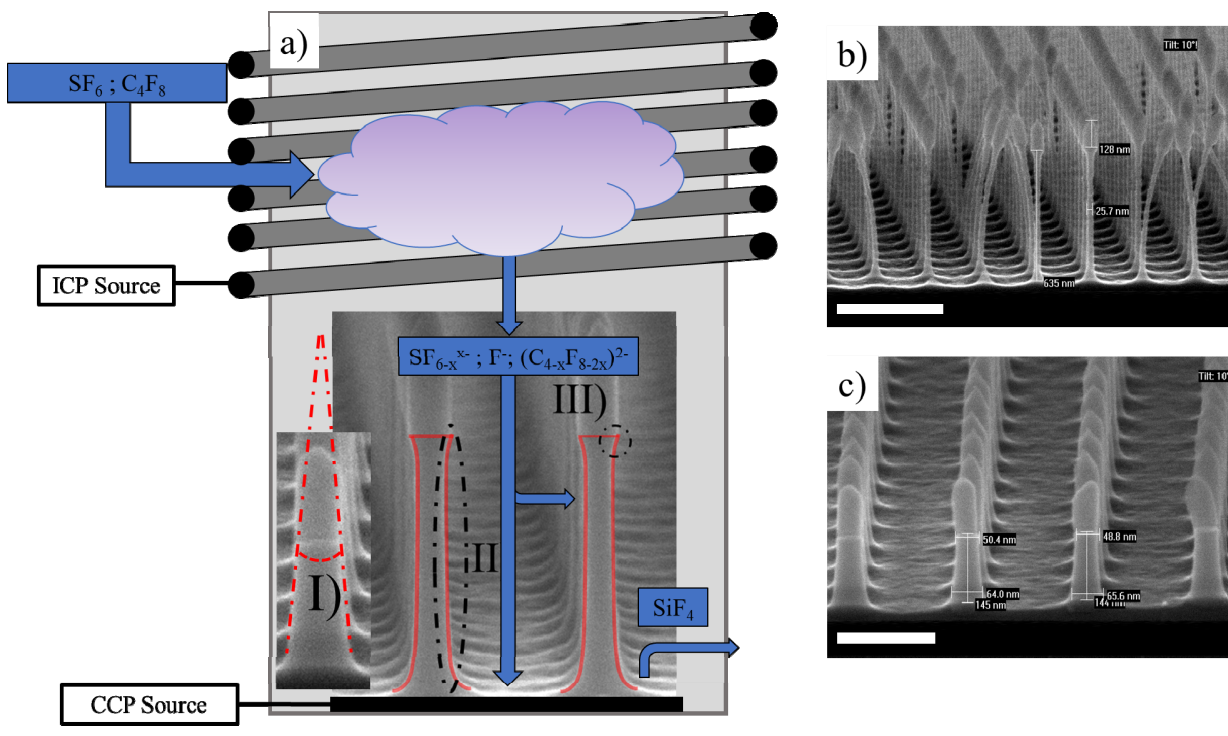

The effect of the variation of the process parameters in Table 2 on the geometry of the SiNWs is evaluated by the under-etching, tapering, barrelling and sidewall roughness, 
and the experimentally observed etch-rate and loading. Under-etching is a higher etch rate just below the etch mask. Barrelling (or bowing) is caused by a thinning of the middle part of the pillar, quantified by $\eta_{B} \equiv D_{B} / D_{i}$, with $D_{B}$ being the smallest SiNW diameter and $D_{i}$ the diameter at the interface with the mask. Tapering is defined by the inclination angle $\theta_{i}$ at the top of the pillars between their sidewalls, defined such that with a positive tapering, the SiNW will be wider at the bottom and for negative tapering, the SiNW is narrower at the bottom compared to the top. See Figure 4 A for sketches. The observed silicon etch-rate, $\lambda_{S i, o b s}$, is equal to the ratio of the height of the SiNW, after etching, and the etch-times. Lastly, the loading is the ratio of the unmasked area and the total substrate area.

Table 2 Different plasma conditions and their effect on the observed etch-rate, $\lambda_{S i, o b s}$, barrelling, $\eta_{B}$, and tapering angle, $\theta_{i}$ See the text for discussions

\begin{tabular}{|c|c|c|c|c|c|c|c|c|}
\hline Run & Figure & $\begin{array}{l}C C P \\
(\mathrm{~W})\end{array}$ & $\begin{array}{c}\text { Pressure } \\
\text { (mTorr) }\end{array}$ & $\begin{array}{c}C_{4} F_{8} \pm 0.2 \\
\quad(\mathrm{sccm})\end{array}$ & $\begin{array}{c}S F_{6} \pm 0.2 \\
(\mathrm{sccm})\end{array}$ & $\begin{array}{c}\lambda_{S i, o b s} \pm 0.2 \\
(\mathrm{~nm} / \mathrm{s})\end{array}$ & $\eta_{B}$ & \\
\hline 1.1 & $4(b)$ & 35 & 22 & 46 & 26 & 10.6 & $0.41 \pm 0.03$ & \\
\hline 1.2 & $\begin{array}{l}\text { Not } \\
\text { shown }\end{array}$ & 35 & 22 & 46 & 23 & 6.5 & $0.70 \pm 0.06$ & 0 \\
\hline 1.3 & $4(c)$ & 35 & 22 & 46 & 20 & 2.4 & $0.94 \pm 0.01$ & $4.7 \pm 0.3$ \\
\hline 3.1 & $5(a)$ & 39 & 22 & 42 & 23 & 7.6 & $0.64 \pm 0.07$ & $1.1 \pm 0.1$ \\
\hline 3.2 & $5(b)$ & 41 & 22 & 42 & 23 & 7.3 & $0.67 \pm 0.07$ & 0 \\
\hline 3.3 & $5(\mathrm{c})$ & 39 & 22 & 48 & 23 & 4.6 & $0.77 \pm 0.03$ & $2.3 \pm 0.1$ \\
\hline 3.4 & $5(d)$ & 41 & 22 & 48 & 23 & 5.5 & $0.95 \pm 0.03$ & $1.2 \pm 0.1$ \\
\hline 4.1 & $6(a)$ & 41 & 16 & 46 & 23 & 5.8 & $0.94 \pm 0.01$ & $2.0 \pm 0.2$ \\
\hline 4.2 & $6(b)$ & 41 & 18 & 46 & 23 & 6.9 & $0.90 \pm 0.04$ & $1.2 \pm 0.2$ \\
\hline 4.3 & $6(c)$ & 41 & 20 & 46 & 23 & 7.1 & $0.83 \pm 0.04$ & $1.3 \pm 0.1$ \\
\hline 4.4 & $6(d)$ & 41 & 22 & 46 & 23 & 7.2 & $0.57 \pm 0.03$ & $1.3 \pm 0.2$ \\
\hline 5.1 & $7(a)$ & 41 & 18 & 45 & 23 & 7.9 & $0.86 \pm 0.02$ & $1.1 \pm 0.1$ \\
\hline 5.2 & $7(b)$ & 41 & 18 & 46 & 23 & 6.9 & $0.90 \pm 0.04$ & $1.2 \pm 0.2$ \\
\hline 5.3 & $7(\mathrm{c})$ & 41 & 18 & 47 & 23 & 6.3 & $0.95 \pm 0.04$ & $1.5 \pm 0.1$ \\
\hline 5.4 & $7(d)$ & 41 & 18 & 48 & 23 & 5.2 & $1.01 \pm 0.05$ & $1.7 \pm 0.2$ \\
\hline
\end{tabular}

\subsection{RIE of silicon in an $\mathrm{SF}_{6} ; \mathrm{C}_{4} F_{8}$ plasma}

In this paragraph, we discuss the effects of varying the process settings and the RIE plasma conditions upon etching SiNWs. The initial process recipe was optimised for etching straight SiNWs of $\sim 250 \mathrm{~nm}$ in height after $60 \mathrm{~s}$ of etching SiNWs under a full-wafer-scale DTL fabricated PFI+BARC mask [4]. Considering a $100 \mathrm{~mm}$ diameter substrate, and $250 \mathrm{~nm}$ wide square unit cell containing the PFI+BARC columns, the silicon loading to which the process was initially optimised was $\sim 87 \%$. In the set of experiments described in this section, the hybrid mask exposes sixteen times a $1.5 \times 4 \mathrm{~mm}^{2}$ area containing $250 \mathrm{~nm}$ wide square unit cells with PFI+BARC columns, yielding a silicon loading of $\sim 1 \%$ which contains significantly less exposed silicon. 
Applying the initial recipe, run 1.1 in Table 2, delivers SiNWs that show a relatively large amount of barrelling, and roughened sidewalls, as measured in Figure 4(b). The effect of the smaller loading is immediately apparent; an extensive amount of barrelling is observed yielding thin SiNWs. The initial full wafer-scale recipe, [4], performs well on the full wafer-scale and is used for the etching of the SiNWs in the case of the fabrication of massively parallel EOF pump, with $50 \mathrm{sccm} \mathrm{C}_{4} \mathrm{~F}_{8}$ flow, but etches too fast on the hybrid mask substrate. Subsequently, the $\mathrm{SF}_{6}$ flow was reduced with $3 \mathrm{sccm}$ to reduce the etch-rate, run 1.2 in Table 2. Indeed, the barrelling and etch-rates are reduced, but the sidewalls are rougher (not shown). Decreasing the $\mathrm{SF}_{6}$ flow with another $3 \mathrm{sccm}$, run 1.3 in Table 2, reduces the barrelling even more, while smoothening the sidewalls but gives a positive taper, see Figure 4(c). Furthermore, in run 1.1 to 1.3 the etch-rate reduces linearly with the $\mathrm{SF}_{6}$ flow, probably due to fewer fluorine radicals being available in the plasma, thus limiting the chemical conversion $\mathrm{Si}$ to $\mathrm{SiF}_{4}$. Subsequently, etching was continued at the lower $\mathrm{SF}_{6}$ mass flow rates because of the $1 \%$ loading under the hybrid mask.

The ion angular distribution function (IADF) and the image force (IF) are assumed to be responsible for the sidewall roughness and barrelling [20]. For the IADF the function is dictated by the distribution of the velocity components being the lateral and vertical velocities of the incoming ionic species. Whenever the mean free path of the ions is larger than the thickness of the sheath (dark space between the plasma and substrate), the lateral component of the velocity is assumed to follow a Maxwell-Boltzmann distribution and is constant across the sheath for a given ionic species and process conditions. The vertical velocity component is dictated by the magnitude of the electric field across the sheath [29]. The IF influences the amount of deflection the ions experience when entering the etched structure and depends on the charging of the sidewalls, which alters the field locally and adds to the lateral velocity component. The IF is most prominent at the mask-substrate interface [30,31]. The amount of charge on the sidewalls depends on the interplay between charge transport at the interface of the bulk material, and the physical and/or chemical adhesion of the ionic constituents. Hence, we varied the applied CCPpower and the applied pressure in order to achieve smoother sidewalls and reduce the barrelling effect.

A set of experiments was conducted where the CCP-power was alternated between $39 \mathrm{~W}$ and $41 \mathrm{~W}$, while, because of the complex interplay between ionic fluxes and etching behaviour, the $\mathrm{C}_{4} \mathrm{~F}_{8}$ flow was alternated between $42 \mathrm{sccm}$ and $48 \mathrm{sccm}$ for a $\mathrm{SF}_{6}$ flow of $23 \mathrm{sccm}$ run 3.1 to 3.4 in Table 2 . In the case of $42 \mathrm{sccm} \mathrm{C}_{4} \mathrm{~F}_{8}$ flow, etching of the sidewalls was significant, see Figure 5(a) and (b), but no effect of the difference CCP power was observed. For the higher $\mathrm{C}_{4} \mathrm{~F}_{8}$ flows, a significant reduction of the barrelling is observed with tapering in the case of $39 \mathrm{~W}$ CCP. For the highest CCP setting the barrelling is almost completely absent, possibly due to a reduction of the IADF as a function increased applied CCP-power. For both CCP power values an increase in $\mathrm{C}_{4} \mathrm{~F}_{8}$ flows yielded a decrease in etch-rate. However, the SiNWs still show significant sidewall roughness.

To further reduce the IADF, an experiment was conducted in which the applied pressure was varied to observe the effect on the barrelling, tapering, sidewall roughness and etch-rates for silicon and the mask material (run 4.1-4.4 in Table 2). The resulting 
SiNWs are shown in Figure 6(a)-(d). The observed etch-rates for Si (the mask) are shown in Figure 6(e) (inset), while Figure 6(d) shows the Si to mask etching selectivity. With increasing pressures, the barrelling becomes more pronounced while increasing the positive taper, the $\mathrm{Si}$ etch-rate increases and converges, while the mask etch-rate decreases, yielding a higher etch selectivity towards $\mathrm{Si}$.

Figure 5 (a)-(d) SEM micrographs for RIE experiments where the CCP power was varied, specific process conditions are found in Table 2 run 3.1 to 3.4. The SiNWs still contain the PFI+BARC mask and were imaged directly after RIE of silicon. Scale bars represent $200 \mathrm{~nm}$
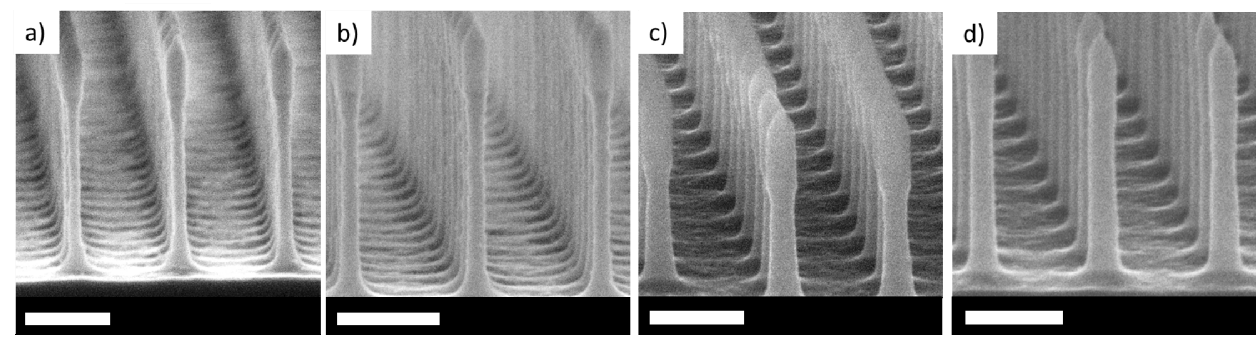

Figure 6 (a)-(d) SEM micrographs showing cross-sections of fabricated SiNWs in run 4.1 to 4.4 from Table 2. The scale bars represent $200 \mathrm{~nm}$. (e) $\lambda_{S i, o b s}$ and $\lambda_{\text {mask,obs }}$ (inset), and (f) selectivity towards Si etching against the applied process pressure. The graphs contain an interval plot showing a confidence interval of $95 \%$ for 5 measurements on a single substrate at different locations

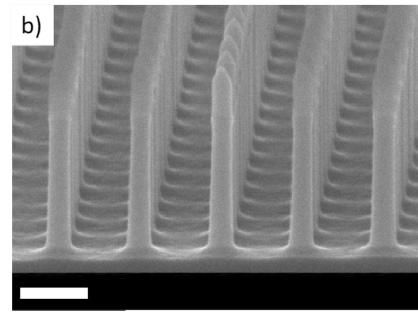

a)

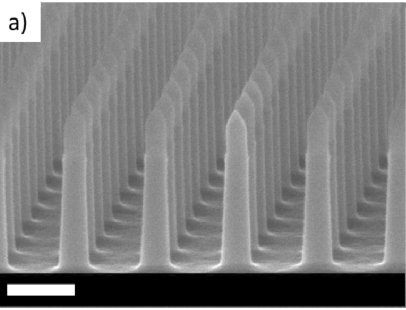

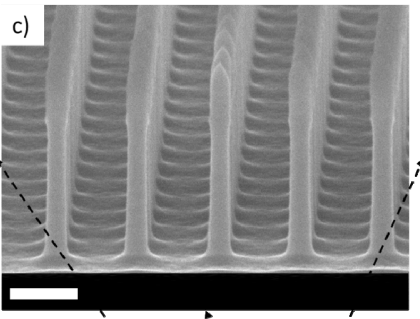

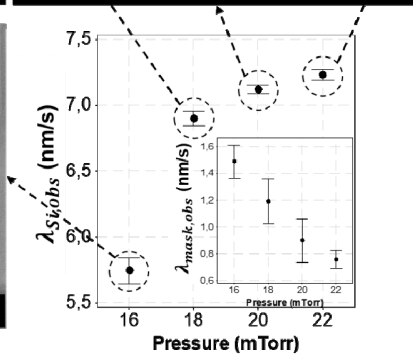

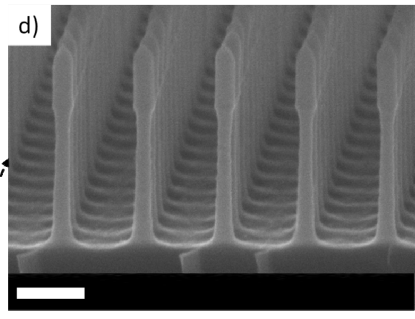

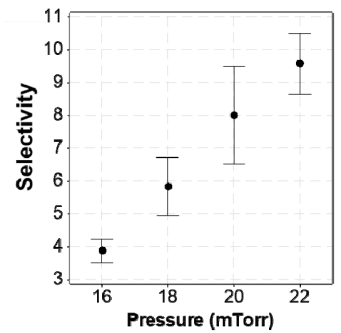

Finally, a set of experiments is conducted at $18 \mathrm{mTorr}$ of applied pressure, varying the $\mathrm{C}_{4} \mathrm{~F}_{8}$ flow, run 5.1-5.4 in Table 2. The results are shown in Figure 7. An increase in $\mathrm{C}_{4} \mathrm{~F}_{8}$ flow gives less barrelling, more positive tapering, a lower silicon etch-rate, and reduced selectivity towards $\mathrm{Si}$. The reduced selectivity is a result of a reduction in $\lambda_{S i, \text { obs }}, \lambda_{\text {mask obs }}$ shows no significant variation. 
Figure 7 Results for a varying $\mathrm{C}_{4} \mathrm{~F}_{8}$ flow, run 5.1 to 5.4 in Table 2. (a)-(d) show the fabricated SiNWs (Scale bars represent $200 \mathrm{~nm}$ ), (e) $\lambda_{S i, o b s}$ and $\lambda_{\text {mask,obs }}$ (inset), and (f) selectivity towards Si etching against the applied $\mathrm{C}_{4} \mathrm{~F}_{8}$ flow. The graphs contain an interval plot showing a confidence interval of $95 \%$ for 5 measurements on a single substrate at different locations
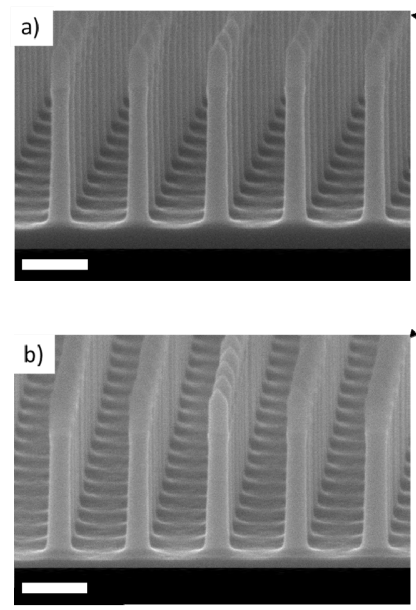
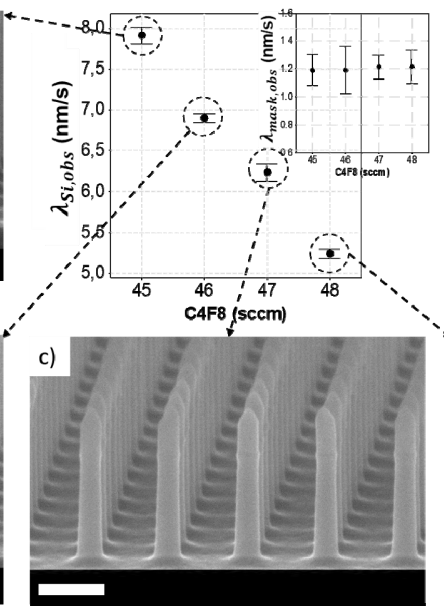
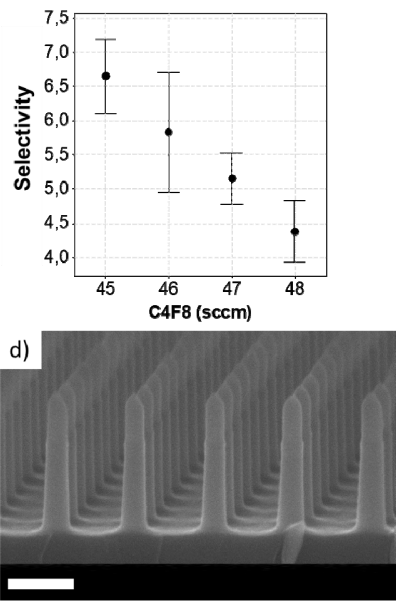

\subsection{Electrical characterisation of LAFE devices}

The electrical characterisation of four fabricated LAFE devices was performed by (V, I)measurements to determine cold field emission performance. The fabrication outcome of the tested devices is shown in Figure 8. The tested devices contained a $1.5 \times 4 \mathrm{~mm}^{2}$ LAFE, each composed of $\sim 9.6 \cdot 10^{7} \mathrm{SiNWs}$. Before characterisation, samples were cleaned as described in the experimental section, yielding the SiNWs as shown in the top-right corner of Figure 3.

Figure 8 The figures show the fabrication details of the test devices. In (i) A photograph of a $100 \mathrm{~mm}$ silicon substrate containing sixteen $1.5 \times 4 \mathrm{~mm}^{2}$ LAFE devices. (ii) close up of a single diced LAFE device containing both a $500 \mathrm{~nm} \mathrm{siO}{ }_{2}$ spacer layer and a $230 \mu \mathrm{m}$ high plateau with a $1 \times 1 \mathrm{~cm}^{2}$ area. (iii) Cross-sectional SEM image of the edge of the nanowire array, scale bar represents $1 \mu \mathrm{m}$. (iv) Cross-sectional SEM image displaying both the spacer layer and plateau, scale bar represents $1 \mathrm{~mm}$. The plateau was achieved by RIE, masking the $1 \times 1 \mathrm{~cm}^{2}$ area with a positive tone photoresist (see online version for colours)
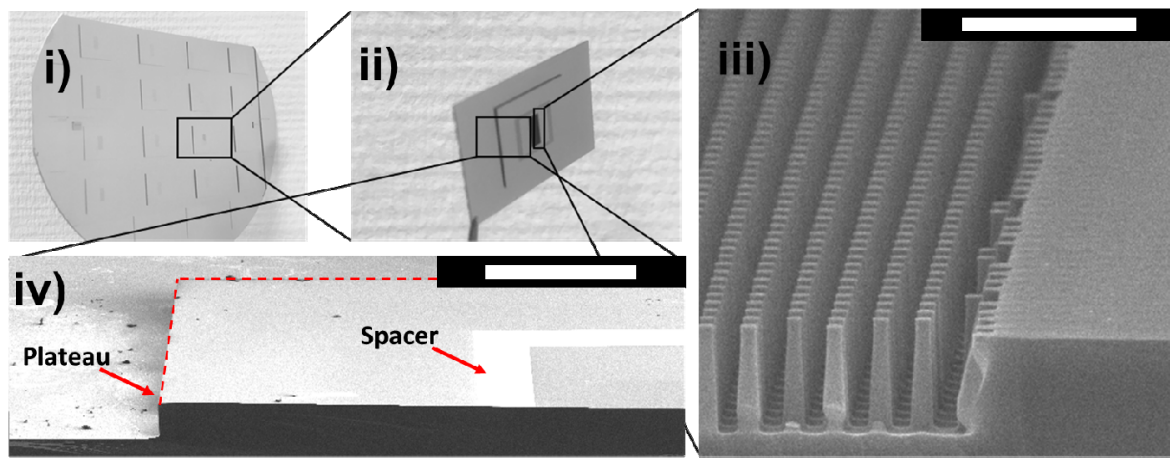
The test setup consisted of a vertically suspended stainless-steel rod connected to a strain gauge (LSM250, Futek) and a piezo element (P-603.3S1, PI). The rod was pressed against a flat counter electrode contacting the $500 \mathrm{~nm} \mathrm{SiO}_{2}$ spacer layer and retracted until barely touching. Voltage sweeps were performed between $0-20 \mathrm{~V}$ at increments of $0.1 \mathrm{~V}$ every $2 \mathrm{~s}$, measuring the current by employing a source measuring unit $(2410$, Keithley) connected to a LabView interface through GPIB. The readout was performed $300 \mathrm{~ms}$ before the next increment with an integration window of $200 \mathrm{~ms}$ and a sampling frequency of $50 \mathrm{~Hz}$.

Analysis of the measurements through the Fowler-Nordheim (FN) plots are displayed in Figure 9. The values of the macroscopic field, $E_{0}$, can be recalculated from the applied potential and the gap defined by the $500 \mathrm{~nm}$ spacer layer constructing the tip-toanode distance. The current density, $J$, is extracted by dividing the measured current by the macroscopic $1.5 \times 4 \mathrm{~mm}^{2}$ LAFE footprint area. The near-linear behaviour in the FN plot indicates that field emission was indeed observed [32,33]. No additional effort was made to extract the field enhancement factor since the imposed experimental conditions require a more thorough analysis which we consider out of scope for this work [34-36].

Figure 9 Measurement data obtained by electrical characterisation $(V, I)$ of four different LAFE devices. The $V, I$ data is plotted in a characteristic Fowler Nordheim-plot (see online version for colours)

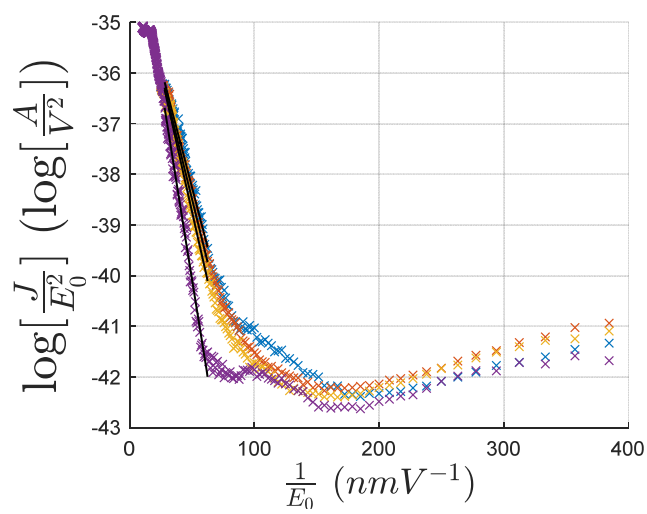

\subsection{Massive parallel nano-pore based EOF-pump}

The EOF pumping mechanism is based on the electrical double layer (EDL) that forms at the negatively charged walls of the silicon oxide coated pores when submerged [36]. When applying a potential gradient parallel to the surface the dominantly positive ions in the EDL will move accordingly while also moving the nearby water through drag [37]. Since the working mechanism of the EOF-pump is based on the oxide layer that is thermally grown directly after the fabrication of the SiNWs, Figure 2(a), additional fabrication steps were taken to guarantee the quality at the end of the fabrication process.

During the fabrication as described in Section 2.4, a two-step etching of the bulk was chosen because 
1 the increased etch-rate of $\mathrm{KOH}$ vs. TMAH enables rapid bulk silicon etching, Figure 2(c)

2 the high selectivity of $5.0 \times 10^{3}$ for TMAH etching of silicon compared to $\mathrm{SiO}_{2}$.

When removing the last $80 \mu \mathrm{m}$ of silicon, this selectivity preserves the integrity of the $\mathrm{SiO}_{2}$ walls inside the nanopores, Figure 2(d). After this, the nanopores were again filled with poly-Si which was then subsequently oxidised, to create a hard mask for the protection of the $\mathrm{SiO}_{2}$ walls of the nanopores during further processing, Figure 2(e).

When removing the last front side $\mathrm{SiRN}$ using $\mathrm{H}_{3} \mathrm{PO}_{4}$, the $\mathrm{SiO}_{2}$ on top of the embedded nanopores stays intact due to the selectivity of 9.6 for $\mathrm{SiRN}$ over $\mathrm{SiO}_{2}$, thereby allowing a little over-etching to ensure all tops are uncovered Figure 2(f). Results of the membrane fabrication immediately after the last SiRN etching step in $\mathrm{H}_{3} \mathrm{PO}_{4}$, Figure $2 \mathrm{e}$ ), are shown in Figure 10(a)-(c). The original nanopillars composed of $<001>\mathrm{Si}$ and the nanopores, now filled with poly-Si, are visible and show up as different colours on the SEM images.

Figure 10 SEM images of the fabrication of the nanopore membrane. Images (a)-(c) were taken right after the last $\mathrm{H}_{3} \mathrm{PO}_{4}$ etching step also shown in Figure 2(d). (a) A $100 \times 100 \mu \mathrm{m}^{2}$ square membrane that snapped during dicing of the sample before taking the crosssection image. (b) Close-up of the transition from the SiRN layer to the edge of the etched free window and the free-hanging SiRN membrane. (c) Closeup of the edge of the membrane, still showing the crystalline (white, red arrows) si pillars on the left and the poly-si (dark grey, blue arrows) filled nanopores on the right. (d) The cross-section of a broken membrane (with a piece of the collapsed membrane below it) (see online version for colours)
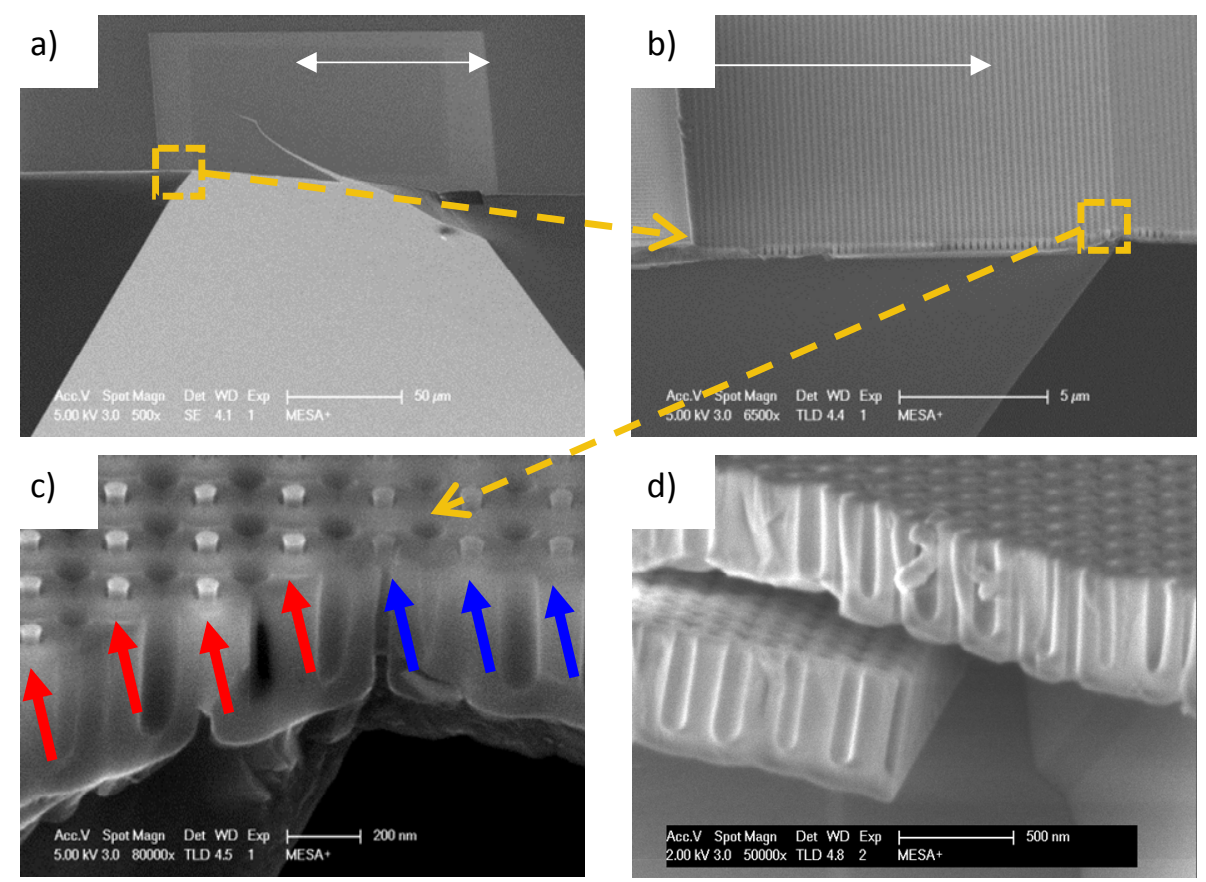
In addition to nanopores, cavities are observed at the corner points of the SiNW centred unit cell. The cavities are a result of the conformal deposition of SiRN on the slightly barrelled SiNWs which, in turn, are formed during the employed RIE process. During the deposition, the SiRN grows conformally around the SiNWs. The interfaces of the growing SiRN fronts meet first halfway between the closest neighbours and finally meet halfway between the next nearest neighbours (in the middle of the diagonal for a square unit cell). Because the deposition is conformal, and the distance between the SiNWs varies over the height of the SiNWs in the case of a barrelled SiNW, the interface meets at the top first, enclosing cavities at the diagonal. Since the isotropic wet-chemical etching of SiRN is performed with a slight over-etching, the cavities are opened-up and enlarged.

However, for the strength of the membrane, not the cavities but the material at the top and bottom of the membrane are the most important. The bottom layer is left fully intact and at the top layers, all $83 \pm 3 \mathrm{~nm}$ wide and $455 \pm 5 \mathrm{~nm}$ long nanopores are still connected by the SiRN. A cross-section of the final membrane can be seen in Figure 10. The nanopores can be seen, as well as the cavities. The figure shows there is still a significantly thick layer of SiRN on the sides of the nanopores to structurally support the membrane and allow it to withstand pressures in the order of $\sim 0.1 \mathrm{MPa}$.

To confirm the integrity and strength of the membrane, a pressure test has been performed on one of the membranes. A $1 \mathrm{~cm}^{2}$ chip containing 37 squares with $100 \times 100 \mu \mathrm{m}^{2}$ membranes was placed in a chip-holder containing water reservoirs, Figure 11, which was filled with water and connected to a pressure regulator (IR1020F01, SMC) in series with a pressurised air outlet. The pressure was monitored by a digital pressure sensor (PU5404, IFM Electronic) connected to a panel meter (SGD 24-M, Lascar PanelPilot). The pressure was gradually increased and showed a breaking/rupture of the membrane at $180 \mathrm{kPa}$.

\subsection{Testing of massive parallel nano-pore based EOF-pump}

For testing, a $1 \mathrm{~cm}^{2}$ chip with $37100 \times 100 \mu \mathrm{m}^{2}$ membranes containing a total of $5.92 \times 10^{6}$ pores with a $455 \pm 5 \mathrm{~nm}$ length and $83 \pm 3 \mathrm{~nm}$ diameter, was placed in a chip-holder between two Plexiglas reservoirs containing platinum wire-electrodes and height measurement columns, Figure 11. The setup was current-controlled and the $117 \mathrm{mV}$ cross-membrane voltage is a calculated value based on the applied constant $20 \mathrm{~mA}$ current (6221, Keithley) in combination with the conductivity of the solution and membrane geometry.

Preliminary tests with a $0.1 \mathrm{M}$ buffered potassium phosphate solution $\left(\mathrm{K}_{2} \mathrm{HPO}_{4}\right.$ and $\mathrm{KH}_{2} \mathrm{PO}_{4}$ ) with a $\mathrm{pH} \sim 8$ were performed at the effective calculated $117 \mathrm{mV}$ crossmembrane voltage, corresponding to an applied voltage in the $10-40 \mathrm{~V}$ range. A maximum flow of around $13 \mu \mathrm{L} / \mathrm{min}$ or $30 \mathrm{~mL} /\left(\operatorname{min~} \mathrm{V} \cdot \mathrm{cm}^{2}\right)$ was found with a calculated maximum back-pressure of $14 \mathrm{kPa}$ or $120 \mathrm{kPa} / \mathrm{V}$ at $117 \mathrm{mV}$ applied effective potential.

Comparing this to other devices; most EOF pumps show a trade-off between flow and pressure and operate at high voltages $\left(10^{2}-10^{3} \mathrm{~V}\right)$ with $\mathrm{mL} / \mathrm{min}$ flowrates or $\mathrm{kPa}$ to $\mathrm{MPa}$ pressures. Regarding high flow rates, a fritted glass EOF pump was reported that produces a flow of $33 \mathrm{~mL} / \mathrm{min}$ and withstands a maximum pressure of $132 \mathrm{kPa}$ at $100 \mathrm{~V}$ applied electric potential, converting to $26 \mu \mathrm{L} /\left(\mathrm{min} \cdot \mathrm{V} \cdot \mathrm{cm}^{2}\right)$ and $1.32 \mathrm{kPa} / \mathrm{V} \mathrm{[38].} \mathrm{In} \mathrm{the}$ high-pressure regime, a packed capillaries pump was reported with a flow of $4.5 \mathrm{~nL} / \mathrm{min}$ at a pressure of $40 \mathrm{MPa}$ at $1.5 \mathrm{kV}$ applied voltage yielding $26 \mu \mathrm{L} /\left(\mathrm{min} \cdot \mathrm{V} \cdot \mathrm{cm}^{2}\right)$ and 
$27 \mathrm{kPa} / \mathrm{V}$ [15]. For an overall balanced performance between flow and pressure, a packed capillary pump producing $5 \mathrm{~mL} / \mathrm{min}$ at $1 \mathrm{MPa}$ at $15 \mathrm{~V}$ of applied electric potential was reported, giving $7 \mathrm{~mL} /\left(\mathrm{min} \cdot \mathrm{V} \cdot \mathrm{cm}^{2}\right)$ and $69 \mathrm{kPa} / \mathrm{V}$ [14]. From this, we conclude to have realised a state-of-the-art performance with a massively parallel nano-pore based EOF-pump combining high generated flowrates and pressures with excellent mechanical stability.

Figure 11 Left: A sketch of the used measurement setup with the membrane (red) in the middle [13]. Right: normalised water volume in the column with the rising buffer solution. Lines: average and $95 \%$ confidence interval. Blue dots: measurement data (see online version for colours)
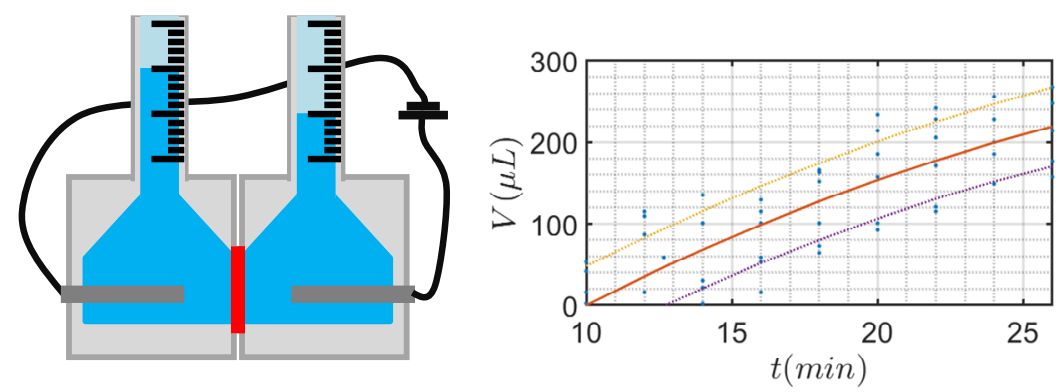

Source: Kooijman et al. [13]

\section{Conclusion}

We have introduced a technology platform based on vertical SiNW arrays fabricated by a displacement Talbot lithography and additive hybrid lithography combined with reactive ion etching. The introduction of the additive hybrid lithography enables the combination of a nanoscale and microscale photoresist structure, preserving the integrity of the nanoscale pattern. Optimisation of the reactive ion etching recipe applied to a hybrid mask led to vertical SiNWs with smooth and straight sidewalls, diameters between $70-100 \mathrm{~nm}$, being up to $700 \mathrm{~nm}$ in length, and arranged in a $250 \mathrm{~nm}$ pitch square unit cell. The nanowires were embedded in a dielectric ceramic membrane, which was made free-standing to access both sides of the pillars in a two-step etching process. The versatility of the platform is illustrated by device implementations in the nano-electronic and nanofluidic domains. The combination with crystallographic nanolithography for detailed shaping and functionalisation of the nanowires is expected to further increase the opportunities offered by this platform.

\section{Acknowledgements}

This work was supported by the Netherlands Centre for Multiscale Catalytic Energy Conversion (MCEC), an NWO Gravitation program funded by the Ministry of Education, Culture and Science of the government of the Netherlands. The authors gratefully acknowledge the extensive support from the MESA + NanoLab staff. 


\section{References}

1 Chen, S.H., Lue, H.T., Shih, Y.H., Chen, C.F., Hsu, T.H., Chen, Y.R., Hsiao, Y.H., Huang, S.C., Chang, K.P., Hsieh, C.C., Lee, G.R., Chuang, A.T.H., Hu, C.W., Chiu, C.J., Lin, L.Y., Lee, H.J., Tsai, F.N., Yang, C.C., Yang, T. and Lu, C.Y. (2012) 'A highly scalable 8-layer Vertical Gate 3D NAND with split-page bit line layout and efficient binary-sum MiLC (Minimal Incremental Layer Cost) staircase contacts', Tech. Dig. - Int. Electron Devices Meet. IEDM, pp.2.3.1-2.3.4.

2 Nitayama, A. and Aochi, H. (2011) 'Vertical 3D NAND flash memory technology', ECS Transactions, Vol. 41, No. 7, pp.15-25.

3 Mustonen, A., Guzenko, V., Spreu, C., Feurer, T. and Tsujino, S. (2014) 'High-density metallic nano-emitter arrays and their field emission characteristics', Nanotechnology, Vol. 25, No. 8, pp.1-6.

4 Pordeli, Y., Borgelink, B.T.H., van der Wel, B.Y., Berenschot, E.J.W., Dogan, T., de Boer, M.J., Bruinink, C.M., Zandvliet, H.J.W., Gardeniers, H.J.G.E. and Tas, N.R. (2019) 'Wafer-scale self-aligned fabrication of nanometric curved tunneling junctions', 2019 20th International Conference on Solid-State Sensors, Actuators and Microsystems and Eurosensors XXXIII (TRANSDUCERS and EUROSENSORS XXXIII), June, pp.2376-2379.

5 Berenschot, J.W., Sun, X., Le The, H., Tiggelaar, R.M., De Boer, M.J., Eijkel, J.C.T., Gardeniers, J.G.E., Tas, N.R. and Sarajlic, E. (2017) 'Wafer-scale nanostructure formation inside vertical nano-pores', 2017 IEEE 12th Int. Conf. Nano/Micro Eng. Mol. Syst. NEMS 2017, Los Angeles, USA, Vol. 1, pp.57-60.

6 Berenschot, E.J.W., Burouni, N., Schurink, B., Van Honschoten, J.W., Sanders, R.G.P., Truckenmuller, R., Jansen, H.V., Elwenspoek, M.C., Van Apeldoorn, A.A. and Tas, N.R. (2012) '3D nanofabrication of fluidic components by corner lithography', Small, Vol. 8, No. 24, pp.3823-3831.

7 Burouni, N., Berenschot, E., Elwenspoek, M., Sarajlic, E., Leussink, P., Jansen, H. and Tas, N. (2013) 'Wafer-scale fabrication of nanoapertures using corner lithography', Nanotechnology, Vol. 24, No. 28.

8 Berenschot, J.W. (n.d.) Self-Multiplication of Silicon Wedges by Convex Corner Lithography, Manuscript in Preparation, n.d. 2020.

9 Jonker, D., Tiggelaar, R.M., Berenschot, J.W., Tas, N.R., Van Houselt, A., Zandvliet, H.J.W. and Gardeniers, J.G.E. (2019) 'High-throughput DTL/optical-hybrid lithography for fabricating high-density silicon nanowire arrays', $M N E$ 2019, p.1.

10 Graves, W.S., Kärtner, F.X., Moncton, D.E. and Piot, P. (2012) 'Intense superradiant x rays from a compact source using a nanocathode array and emittance exchange', Phys. Rev. Lett., Vol. 108, No. 26, pp.1-5.

11 Lewellen, J.W. and Noonan, J. (2005) 'Field-emission cathode gating for RF electron guns', Phys. Rev. Spec. Top. -Accel. Beams, Vol. 8, No. 3, pp.55-63.

12 Upadhyayula, V.K.K., Meyer, D.E., Curran, M.A. and Gonzalez, M.A. (2014) 'Evaluating the environmental impacts of a nano-enhanced field emission display using life cycle assessment: a screening-level study', Environ. Sci. Technol., Vol. 48, No. 2, pp.1194-1205.

13 Kooijman, L.J., Pordeli, Y., Van Der Wel, B.Y., Berenschot, E.W., Eijkel, J.C.T. and Tas, N.R. (2019) High-Performance Ceramic Eof Pump Realized By Massively Parallel Sacrificial Silicon Nano-Pillar Moulding, October, pp.1188-1189.

14 Wang, X., Cheng, C., Wang, S. and Liu, S. (2009) 'Electroosmotic pumps and their applications in microfluidic systems', Microfluid. Nanofluid., Vol. 6, No. 2, pp.145-162.

15 Jiang, L., Mikkelsen, J., Koo, J.M., Huber, D., Yao, S., Zhang, L., Zhou, P., Maveety, J.G., Prasher, R., Santiago, J.G., Kenny, T.W. and Goodson, K.E. (2002) 'Closed-loop electroosmotic microchannel cooling system for VLSI circuits', IEEE Trans. Compon. Packag. Technol., Vol. 25, No. 3, pp.347-355. 
16 Solak, H.H., Dais, C. and Clube, F. (2011) 'Displacement Talbot lithography: a new method for high-resolution patterning of large areas', Opt. Express, Vol. 19, No. 11, p.10686.

17 Le-The, H., Berenschot, E., Tiggelaar, R.M., Tas, N.R., van den Berg, A. and Eijkel, J.C.T. (2017) 'Shrinkage control of photoresist for large-area fabrication of Sub-30 nm periodic nanocolumns', Adv. Mater. Technol., Vol. 2, No. 3.

18 Jansen, H., Gardeniers, H., De Boer, M., Elwenspoek, M. and Fluitman, J. (1996) 'A survey on the reactive ion etching of silicon in microtechnology', J. Micromech. Microeng., Vol. 6, No. 1, pp.14-28.

19 Franz Laermer, R.B.G. and Schilp, A. (1993) Method of Anisotropically Etching Silicon, US5501893A Patent, US Pat. 5501893.

20 Jansen, H.V., De Boer, M.J., Unnikrishnan, S., Louwerse, M.C. and Elwenspoek, M.C. (2009) 'Black silicon method X: a review on high speed and selective plasma etching of silicon with profile control: an in-depth comparison between Bosch and cryostat DRIE processes as a roadmap to next generation equipment', J. Micromech. Microeng., Vol. 19, No. 3, pp.1-41.

21 Kiihamäki, J. and Franssila, S. (1999) 'Pattern shape effects and artefacts in deep silicon etching', J. Vac. Sci. Technol., A Vacuum, Surfaces, Film., Vol. 17, No. 4, pp.2280-2285.

22 de Boer, M.J., Gardeniers, J.G.E., Jansen, H.V., Smulders, E., Gilde, M-J., Roelofs, G., Sasserath, J.N. and Elwenspoek, M. (2002) 'Guidelines for etching silicon MEMS structures using fluorine high-density plasmas at cryogenic temperatures', J. Microelectromech. Syst., Vol. 11, No. 4, August, pp.385-401.

23 Ishchuk, V., Volland, B.E. and Rangelow, I.W. (2014) 'ViPER: Simulation software for high aspect ratio plasma etching of silicon', Microsyst. Technol., Vol. 20, Nos. 10-11, pp.1791-1796.

24 Chang, B., Jensen, F., Hübner, J. and Jansen, H. (2018) 'DREM2: a facile fabrication strategy for freestanding three dimensional silicon micro- and nanostructures by a modified Bosch etch process', J. Micromech. Microeng., Vol. 28, No. 10.

25 Solanki, A. and Um, H. (2018) Top-Down Etching of Si Nanowires, 1st ed., Vol. 98, Elsevier Inc..

26 Jansen, H., De Boer, M., Legtenberg, R. and Elwenspoek, M. (1995) 'The black silicon method: A universal method for determining the parameter setting of a fluorine-based reactive ion etcher in deep silicon trench etching with profile control', J. Micromech. Microeng., Vol. 5, No. 2, pp.115-120.

27 Ishikawa, K., Karahashi, K., Ishijima, T., Il Cho, S., Elliott, S., Hausmann, D., Mocuta, D., Wilson, A. and Kinoshita, K. (2018) 'Progress in nanoscale dry processes for fabrication of high-aspect-ratio features: How can we control critical dimension uniformity at the bottom?', Jpn. J. Appl. Phys., Vol. 57, No. 6.

28 Wright, D.R., Hartman, D.C., Sridharan, U.C., Kent, M., Jasinski, T. and Kang, S. (1992) 'Low temperature etch chuck: modeling and experimental results of heat transfer and wafer temperature', J. Vac. Sci. Technol., A Vacuum, Surfaces, Film., Vol. 10, No. 4, pp.1065-1070.

29 Hauguth, M., Volland, B.E., Ishchuk, V., Dressler, D., Danz, T., Rangelow, I.W., Kokkoris, G., Gogolides, E., Goodyear, A. and Cooke, M. (2009) 'Integrated plasma processing simulation framework, linking tool scale plasma models with 2D feature scale etch simulator', Microelectron. Eng., Vol. 86, No. 4-6, pp.976-978.

30 Coburn, J.W. and Winters, H.F. (1989) 'Conductance considerations in the reactive ion etching of high aspect ratio features', Appl. Phys. Lett., Vol. 55, No. 26, pp.2730-2732.

31 Zhang, P. (2019) 'Relationship between edge roughness in mask pattern and charging in plasma etching', Plasma Process. Polym., Vol. 17, September, pp.1-11.

32 Stern, T.E., Gossling, B.S. and Fowler, R.H. (1929) 'Further studies in the emission of electrons from cold metals', Proc. R. Soc. London. Ser. A, Contain. Pap. a Math. Phys. Character, Vol. 124, No. 795, July, pp.699-723.

33 Houston, J.M. (1952) 'The slope of logarithmic plots of the Fowler-Nordheim equation', Phys. Rev., Vol. 88, No. 2, p.349. 
34 Forbes, R.G. (2013) 'Development of a simple quantitative test for lack of field emission orthodoxy', Proc. R. Soc. A Math. Phys. Eng. Sci., Vol. 469, No. 2158.

35 Popov, E.O., Kolosko, A.G. and Filippov, S.V. (2019) 'Electrical field admissible values for the classical field emitter regime in the study of large area emitters', $A I P A d v$., Vol. 9, No. 1.

36 Forbes, R.G.(2019) 'The Murphy-Good plot: a better method of analysing field emission data', R. Soc. Open Sci., Vol. 6, No. 12, December, p.190912.

37 Qiao, R. and Aluru, N.R. (2004) 'Charge inversion and flow reversal in a nanochannel electro-osmotic flow’, Phys. Rev. Lett., Vol. 92, No. 19, pp.1-4.

38 Yao, S., Hertzog, D.E., Zeng, S., Mikkelsen, J.C. and Santiago, J.G. (2003) 'Porous glass electroosmotic pumps: Design and experiments', J. Colloid Interface Sci., Vol. 268, No. 1, pp.143-153. 